\title{
Symposium review: Milk fat globule size: Practical implications and metabolic regulation*
}

\section{Nurit Argov-Argaman†}

Department of Animal Science, the Robert H. Smith Faculty of Agriculture, Food and Environment, the Hebrew University of Jerusalem, Israel, POB 76100

\section{ABSTRACT}

Milk fat globule (MFG) size ranges over 3 orders of magnitude, from less than $200 \mathrm{~nm}$ to over $15 \mu \mathrm{m}$. The significance of MFG size derives from its tight association with its lipidome and proteome. More specifically, small MFG have relatively higher content of membrane compared with large globules, and this membrane exerts diverse positive health effects, as reported in human and animal studies. In addition, MFG size has industrial significance, as it affects the physicochemical and sensory characteristics of dairy products. Studies on the size regulation of MFG are scarce, mainly because various confounders indirectly affect MFG size. Because MFG size is determined before and during its secretion from mammary epithelial cells, studies on the size regulation of its precursors, the intracellular lipid droplets (LD), have been used as a proxy for understanding the mechanisms controlling MFG size. In this review, we provide evidence for 2 distinct mechanisms regulating LD size in mammary epithelial cells: co-regulation of fat content and triglyceride-synthesis capacity of the cells, and fusion between LD. The latter is controlled by the membrane's polar lipid composition and involves mitochondrial enzymes. Accordingly, this review also discusses MFG size regulation in the in vivo metabolic context, as MFG morphometric features are often modulated under conditions that involve animals' altered energy status.

Key words: milk fat globule, membrane, lipid droplet, phosphatidylethanolamine, mitochondria

\section{INTRODUCTION}

Dairy products are among the main sources of fat and protein in the Western diet. Therefore, as a strat-

Received June 19, 2018.

Accepted November 12, 2018.

*Presented as part of the Joint MILK/Lactation Biology Symposium: Milk Globules, Vesicles, and Exosomes-Update, Origin, Structure, and Function at the ADSA Annual Meeting, Knoxville, Tennessee, June 2018.

†Corresponding author: argov.nurit@mail.huji.ac.il egy to improve dietary composition, efforts have been made to increase the content of bioactive components in dairy products. In the context of milk lipids, many studies have been published on the mechanisms controlling fatty acid (FA) composition in milk. Nevertheless, milk FA are almost never secreted in their free form, but as part of the milk fat globule (MFG). The MFG consists of a triglyceride $(\mathbf{T g})$ core covered with 3 layers of phospholipids $(\mathbf{P l})$ and proteins derived from the mammary gland cellular membranes, termed MFG membrane (MFGM). The MFG size ranges from 200 $\mathrm{nm}$ to more than $15 \mu \mathrm{m}$ in various mammalian species (Mulder and Walstra, 1974; Michalski et al., 2005), and its size is tightly associated with the MFGM lipidome and proteome, as demonstrated in dairy cattle (Mesilati-Stahy et al., 2011; Lu et al., 2016). In fact, MFG size determines the surface area and, hence, the amount of coating matter, the MFGM in milk, with higher content for smaller globules due to the higher ratio of surface area to volume in this spherical lipid-protein assembly, as demonstrated in dairy cows (Figure 1). The MFGM has been shown to exert positive effects on human health and, therefore, increasing its content in milk will increase milk nutritional value. Two approaches exist for increasing MFGM content in milk. (1) Preharvest, when milk can be enriched with MFGM if smaller MFG are produced in vivo by the animal (Couvreur et al., 2007; Lopez et al., 2008; Argov-Argaman et al., 2016); or (2) postharvest, via isolation of MFGM from by-products of the cheese and butter pipeline. These by-products are already available commercially and used to fortify milk replacers for infants and in dairy products (Billeaud et al., 2014; Bhinder et al., 2017).

The question of whether pre- and postharvest enrichment of dairy products with MFGM will result in similar health and metabolic effects has yet to be determined. Studies show that bioactive components, such as polyphenols and minerals, are more bioavailable and bioactive when consumed as part of a food matrix compared with supplemented ingredients added to food postharvest (Knowles et al., 2004, 2006). Although there is no evidence of different functionality of MFGM in isolation versus in milk, one can assume 


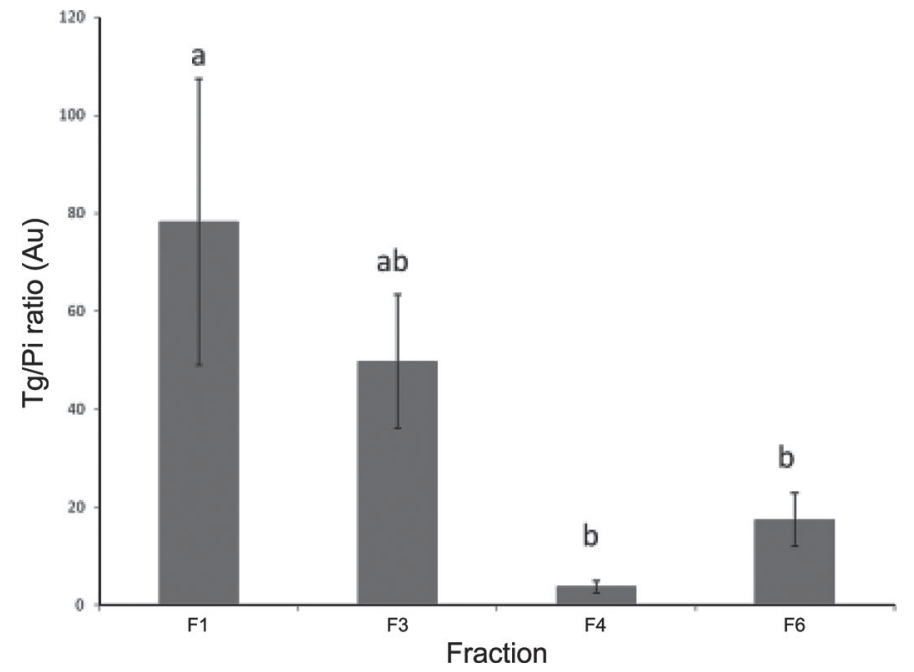

Figure 1. The ratio of triglycerides to phospholipids $(\mathrm{Tg} / \mathrm{Pl})$ is altered concomitantly with milk fat globule (MFG) size. Raw milk from lactating Holstein cows was separated according to Mesilati-Stahy et al. (2011). Of the 6 fractions collected, 4 were significantly differed in terms of size $[\mathrm{F} 1=3.81 \mu \mathrm{m} \pm 0.2(\mathrm{SE}) ; \mathrm{F} 3=3.17 \mu \mathrm{m} \pm 0.2 ; \mathrm{F} 4=$ $3.27 \mu \mathrm{m} \pm 0.06 ; \mathrm{F} 6=1.59 \mu \mathrm{m} \pm 0.04]$. Lipidomics analysis was carried out and the mass ratio between $\mathrm{Tg}$ and the sum of $\mathrm{Pl}$ identified in each size fraction was determined. Results show that smaller MFG contain higher $\mathrm{Pl}$ content than larger MFG. Error bars indicate SE, and different letters $(\mathrm{a}, \mathrm{b})$ indicate significant differences, $P<0.05$.

that it has a greater effect on health and metabolism when consumed as part of milk and not as an isolated ingredient. Thus, revealing the mechanisms underlying the regulation of MFG size is expected to have immense nutritional and health implications. Nevertheless, studies on the mechanism controlling MFG size in vivo are scarce, mostly due to the complexity of the biological processes involved in milk and fat biosynthesis and the variety of confounders that indirectly affect MFG size.

The current review provides some answers regarding the regulatory mechanisms of MFG size, and aims to answer 2 questions: (1) what are the practical implications of MFG size and (2) how is MFG size determined in the mammary gland and in the whole-animal context.

\section{THE LINK BETWEEN MFG SIZE AND COMPOSITION}

The MFG size distribution influences the ratio of membrane material (polar lipids and membrane-bound proteins) to nonpolar $\mathrm{Tg}$, as demonstrated in raw milk (Mesilati-Stahy et al., 2011) and in MFG isolated by microfiltration (Fauquant et al., 2005), with the ratio being greater in small MFG (Figure 1). Although it has received only limited attention, one of the major factors influencing MFG size, and hence MFGM content in milk, is lactation stage. The association between lactation stage and MFG size was indirectly demon- strated by Bitman and Wood (1990), who showed altered Pl-to-Tg ratios in milk during the early, mid, and late lactation stages of dairy cows. These changes reflected altered MFG size, as a negative association was found between Pl-to-Tg ratio and size (Figure 1). Moreover, significant changes in MFG size distribution were demonstrated during the first few days postpartum in human breast milk (Michalski et al., 2005). It was found that within the first $3 \mathrm{~d}$ postpartum, MFG size in human milk shifts from 2 distinct size populations [either extremely large $(\sim 9 \mu \mathrm{m})$ or small MFG $(\sim 0.1 \mu \mathrm{m})]$ to the features found during established lactation - a mean diameter of around $4 \mu \mathrm{m}$. It should be noted that other nanometer-scale structures, such as exosomes, are present in breast milk (Admyre et al., 2007). These are lipid-protein assemblies, 30 to $100 \mathrm{~nm}$ in size. As these nanovesicles are secreted into milk, and are not dissociated by EDTA, which is added to milk samples to dissociate casein micelles, their presence in milk may confound the measurements of MFG size based on light scattering. Nevertheless, MFG have been shown to be secreted in the submicron scale and, therefore, the findings of Michalski et al. (2005) still demonstrate significant alterations in the morphometric features of MFG during the first few days postpartum. It should be emphasized that the change in MFG size distribution early postpartum parallels major changes in the newborn gut, including gut closure that reduces absorption of macromolecules (Leece, 1973). As size determines the content of the bioactive MFGM in milk, with greater content for smaller MFG, these postpartum differences imply that the lactating mother invests extremely costly physiological resources in supplying the suckling neonate with MFGM, which may exert positive effects on development, gut functionality, metabolism, and cognition, as detailed herein; therefore, size can play a central role in these physiological processes. It should also be noted that data on changes in MFG size in early postpartum stages are available for breast milk (Michalski et al., 2005) but not for other species, and the only proxy is the demonstration of altered Pl-to- $\mathrm{Tg}$ ratio throughout bovine lactation (Bitman and Wood, 1990).

\section{MFGM Constituents Affect Health}

To investigate the effect of MFGM proteins and lipids on health, the common approach is to either deconstruct and study each of the MFGM constituents separately or use data mining to identify biological processes in which MFGM proteins might be involved. With respect to proteins, Reinhardt and Lippolis (2008) identified a fraction of MFGM proteins in cow milk as immunomodulators, and therefore concluded that MFGM may 
exert protective functions in the neonate. The effect of MFGM proteins was also elucidated in an intervention study in infant, showing that supplementing infant formula with a commercial protein- rich MFGM from cow milk, resulted in noninferior weight gain compared with breastfed infants (Billeaud et al., 2014). Lu et al. (2016) added the dimension of size, demonstrating that bovine MFG larger than $7 \mu \mathrm{m}$ had higher contents of host defense proteins compared with average-sized MFG $(3.2 \mu \mathrm{m})$, suggesting that the protective attributes of milk can be modulated by controlling MFG size. Unfortunately, the direct relevance of size to health is still unknown, as few studies exist exploring different levels and compositions of dietary MFGM, which mimics the natural association between MFG size and MFGM composition, as found in raw, unprocessed milk.

The MFGM is also a rich source of polar lipids, mainly glycerophospholipids, cholesterol, sphingolipids, and glycoconjugates $(\mathrm{Pl})$. In general, $\mathrm{Pl}$ are recognized as a desirable bioactive component, with numerous studies supporting the beneficial effects of dietary fortification with $\mathrm{Pl}$. However, many of the published studies focused mainly on health risks of adults, especially with respect to heart disease, dyslipidemia, fatty liver, and cancer (Almazov et al., 1986; Bobkova et al., 1989; Klimov et al., 1995; Jiang et al., 2001; Berra et al., 2002; Noh and Koo, 2003; Sakakima et al., 2007, 2009; Cohn et al., 2008; Fukunaga et al., 2008; Zhang et al., 2008; Küllenberg et al., 2012). It should be noted that milk evolved to support the health, development, and survival of infants and newborns, and therefore the health consequences of its consumption should be studied in that context. Unfortunately, only a small subset of studies on health consequences of dietary milk lipid consumption have focused on infants and their health. Nevertheless, data collected on newborns in animal models and infant studies has demonstrated the role of milk polar lipids, constituents of the MFGM, in development and health. For example, in human infants, fortification of milk replacement with sphingomyelin, a major constituent of the MFGM, improved cognitive development at 18 mo of age (Tanaka et al., 2013). In rodents, oral supplementation of sphingomyelin at a young age improved intestinal function (Motouri et al., 2003), whereas gangliosides and sialic acids, also constituents of the MFGM, improved neurodevelopment and cognitive performance (reviewed by Hernell et al., 2016). Collectively, these various studies prove the role for MFGM constituents in development and health in both animal models and humans.

Although positive effects on health were demonstrated for specific MFGM constituents, it seems that when MFGM is provided as an intact structure, including its polar lipid, glycoconjugates, and proteins, it exerts much stronger effects on health and development and confers short- and long-term positive health effects on infants as well as adults. These beneficial effects have been demonstrated in human infants, with improved immunity and intestinal epithelium development (Timby et al., 2014; Timby, 2016), and in murine models, with improved intestinal microbiome upon MFGM dietary supplementation (Bhinder et al., 2017; Li et al., 2018). More specifically, in a mouse model, oral supplementation during infancy of MFGM isolated from bovine milk reduced obesity and weight gain in adulthood (Li et al., 2018). Moreover, infants given formula enriched with MFGM isolated from commercial bovine milk had rates of infection up to the age of 6 mo that were comparable to those in breastfed infants and lower than those in infants fed a standard formula (Timby et al., 2014; Timby, 2016). Moreover, addition of MFGM preparation from commercial bovine milk to rat formula promoted the development of intestinal epithelium and microbiome and protected against colitis induced by gram-positive bacteria (Bhinder et al., 2017). These studies demonstrate the conspicuous benefits of milk lipids in the very young and should encourage the conductance of MFGM research in this context, rather than in the context of metabolic disorders occurring in adulthood.

\section{Practical Implications of MFG Size}

The MFG size has industrial significance in that it affects the physicochemical and sensory characteristics of dairy products; it also affects cheese ripening, as well as shelf life of dairy products (Michalski et al., 2003; O'Mahony et al., 2005; Lopez and Ménard, 2011). In addition, reduced MFG size in cows fed fish meal was associated with softer butter with better cold-spreading ability (Avramis et al., 2003). Camembert cheeses produced from small MFG, separated by microfiltration, had a higher melting point and more elastic texture, a higher flowing aspect, and were less yellow (Michalski et al., 2003).

Therefore, the ability to determine MFG size can lead to new products with different technological and sensory properties (Michalski et al., 2003). It should be noted, however, that dietary-induced changes in MFG size often induce changes in the composition of milk FA (Avramis et al., 2003; Lopez and Ménard, 2011; Argov-Argaman et al., 2014), which may independently change the organoleptic properties of dairy products. An additional and important aspect of size is its potential effect on digestion and postprandial metabolism, an aspect that have been almost completely overlooked. One exception is Baars et al. (2016), who explored the effects of large or small lipid droplets (LD) enveloped 
by a commercial preparation of MFGM on metabolic traits in pre- and postweaning rats. Differences between treatments that were demonstrated in their study were attributed to the greater surface area exposed to pancreatic lipase with decreasing LD size (Armand et al., 1999; Salvia-Trujillo et al., 2013, 2017); however, the aspect of the association between size and composition and its relevance to digestion and metabolism was not addressed. Baars et al. (2016) thus provided the first evidence for the importance of lipid-protein assembly size in terms of metabolism, and this aspect should be further studied to reveal the physiological importance of MFG structure and especially size.

\section{How Size Is Determined: Biosynthesis and Secretion of MFG}

To understand how MFG size is determined, the mechanisms controlling its synthesis and secretion at the molecular, biochemical, and metabolic levels must be elucidated (Figure 2).

Bovine milk fat consists of 95 to $98 \% \mathrm{Tg}$ and only 1 to $5 \% \mathrm{Pl}$, including cholesterol, glycerophospholipids, glycolipids, and sphingolipids (Patton and Jensen, 1975). These ratios are subject to physiological, endocrine, and environmental factors, including, but not limited to, animal species, diet, and lactation stage. The $\mathrm{Pl}$ and $\mathrm{Tg}$ differ in both structure and FA composition, whereas the latter fraction is enriched with short-chain FA and SFA and the former is enriched with long-chain FA and UFA (Dougherty et al., 1987; Bitman and Wood, 1990; RuizSala et al., 1996; Mesilati-Stahy et al., 2012). Studies on the mechanisms controlling the ratio between $\mathrm{Pl}$ and $\mathrm{Tg}$ are still scarce, despite its special importance in the mammary gland due to its potential effect on quality, in terms of organoleptic and health properties, of milk and dairy products. Suggested mechanisms, which may be relevant to various mammalians, include the affinity and efficiency of the enzymes in the Kennedy pathway, which use a mutual substrate, diacylglycerol, to produce $\mathrm{Pl}$ or $\mathrm{Tg}$ (Hammond et al., 2002; Takeuchi and Reue, 2009; Ward, 2015). Specifically, genetic variants of the enzyme diacylglycerol O-acyltransferase (DGAT) differed in the Tg-to-Pl ratio in milk, presumably due to differential enzymatic efficiencies among genotypes (Argov-Argaman et al., 2013). In addition, the availability of long-chain, preformed FA to mammary epithelial cells (MEC) has been suggested as a limiting factor in the synthesis of $\mathrm{Pl}$ in bovine model (Mesilati-Stahy et al., 2012). However, specific and targeted research is warranted to understand the mechanisms controlling the absolute and relative concentrations of $\mathrm{Tg}$ and $\mathrm{Pl}$ in milk.
The FA used by MEC to produce $\mathrm{Pl}$ and $\mathrm{Tg}$ may be the products of de novo synthesis within the mammary gland, or preformed FA absorbed from the capillary bed surrounding the mammary gland alveolar lumen, as demonstrated in mice and bovine models (Kinsella, 1974; Wiking et al., 2004). Most FA synthesized de novo in MEC are short- and medium-chain FA, whereas most of the long-chain FA originate from the circulation as preformed FA (Kinsella, 1974; Corl et al., 2006). These preformed FA can originate from the gastrointestinal tract or from adipose lipolysis. The FA from feed or rumen microbiota are digested and absorbed through the small intestine into the circulation as very low density lipoproteins (VLDL; Olofsson and Borén, 2012). In peripheral tissues, including MEC, VLDL can be endocytosed by MEC-expressed VLDL receptor, and upon fusion with cellular lysosome the FA are released from the glycerol backbone and available for utilization by the cell (Ruby et al., 2010; Olofsson and Borén, 2012); alternatively, Tg hydrolysis can occur in the extracellular compartment, by lipoprotein lipase (pathway 1, Figure 2), at the vascular endothelium in extrahepatic tissues (Teusink et al., 2003). Accumulation of the VLDL-hydrolysis product, free FA (FFA), might allosterically inhibit lipoprotein lipase activity (Bengtsson and Olivecrona, 1980; Peterson et al., 1990) and limit the availability of preformed, long-chain FA to the mammary cells. Another source of preformed, longchain FA is adipose Tg lipolysis, releasing FA to the plasma as albumin-bound nonesterified FA (NEFA). Adipose Tg hydrolysis is induced by catabolic signals, such as glucagon and epinephrine, and executed by hormone-sensitive lipase (Penick and Hinkle, 1963; Adewuyi et al., 2005). Unlike VLDL, NEFA are much more available to peripheral cells, including mammary cells (MEC), as they can diffuse through cellular membranes (pathway 2, Figure 2). Therefore, it is not surprising that an animals' metabolic state is associated with the milk concentration of preformed FA and, in some cases, with MFG size (Mesilati-Stahy et al., 2011; Argov-Argaman et al., 2012, 2014). Nevertheless, the possible role played by the source of the preformed FA (i.e., VLDL vs. NEFA) in MFG size regulation is still overlooked and will be thoroughly discussed further on.

Once in the MEC, FA are transported to the endoplasmic reticulum, where the Tg droplet (pathway 3 , Figure 2) is synthesized, and then released into the cytoplasm covered with $\mathrm{Pl}$ monolayer and specific surface-associated proteins (Mather and Keenan, 1998; Wu et al., 2000; McManaman, 2009). From their site of synthesis, the cytoplasmic LD migrate toward the apical pole of the cell, where they are secreted by an apocrine-like mechanism into the alveolar lumen, en- 


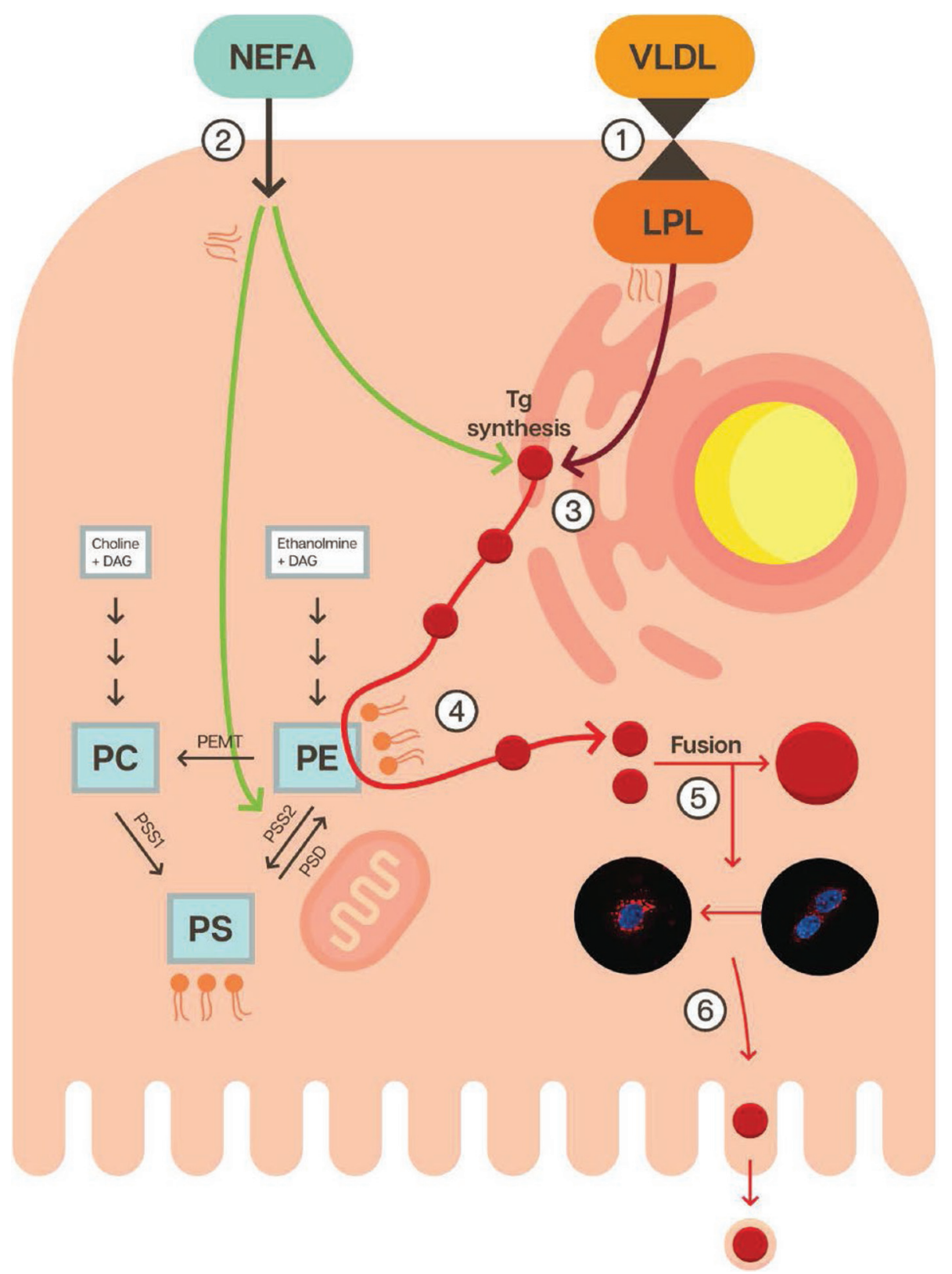

Figure 2. Proposed model of the lipid metabolic pathways involved in size regulation of intracellular lipid droplets (LD) and secreted milk fat globule (MFG). The proposed model includes the absorption of extracellular preformed fatty acids, coupled with triglycerides (Tg) and phospholipid (Pl) synthesis, remodeling of mitochondria activity and membrane composition, and fusion regulation. Long-chain fatty acids are absorbed from exogenous origin as nonesterified fatty acids (NEFA) or as very low density lipoprotein (VLDL)-Tg. Whereas NEFA absorbance may occur by several mechanisms, including diffusion through the plasma membrane with no facilitating mechanism (pathway 2), the VLDL-Tg has to be hydrolyzed first by lipoprotein lipase (LPL) and only thereafter can enter the cell (pathway 1). Therefore, the availability of longchain fatty acids is suggested to be greater when NEFA concentration is elevated. Once in the cell, long-chain fatty acids can be used for Pl or $\mathrm{Tg}$ synthesis in the endoplasmic reticulum (ER; red arrow for VLDL hydrolysis products and green arrow for NEFA) or in the cytoplasm or directly on the LD surface (pathway 3). Additionally, NEFA can increase mitochondria activity and number (green arrow) and, hence, indirectly affect phospholipid composition in the cell, as mitochondria play a role in $\mathrm{Pl}$ synthesis and membrane remodeling (pathway 4). Increases in mitochondria activity and number can induce phosphatidylserine decarboxylase (PSD), a mitochondria enzyme that converts phosphatidylserine (PS) to phosphatidylethanolamine (PE), and increase membrane instability and induce fusion between intracellular LD (pathway 5). Inserts of fluorescence confocal microscopy demonstrate the enhanced fusion, which elevated size of intracellular LD in mammary epithelial cells (MEC; LD stained in red, nucleus stained in blue), as previously demonstrated (Cohen et al., 2018). Eventually, the final phenotype of LD size in the cell will affect the size of the secreted MFG (pathway 6 ). PEMT $=$ phosphatidylethanolamine methyl transferase; PC $=$ phosphatidylcholine; PSS1 $/ 2=$ phosphatidylserine synthase $1 / 2$; green arrows $=$ NEFA-related pathways; red arrows $=$ VLDL-Tg hydrolysis products by LPL-related pathways; green arrows = long-chain fatty acids absorption from NEFA; red arrows = long-chain fatty acids absorption from VLDL hydrolysis; blue arrow $=$ mechanism controlling LD size through its migration from its synthesis location within the ER leaflets to the apical pole of the cell. $\mathrm{DAG}=$ diacylglycerol. 
veloped by the apical cell membrane bilayer (McManaman, 2012). The final contact between the plasma membrane bilayer and the LD surface is mediated through the integral protein butyrophilin (Smoczyński, 2017), which forms a secretion complex with xanthine oxidoreductase, adipophilin, and other proteins on the droplet surface (McManaman, 2009; Monks et al., 2016; Masedunskas et al., 2017).

Eventually, the secreted MFG consists of a Tg core covered with 3 layers of $\mathrm{Pl}$ and proteins - the MFGM (Heid and Keenan, 2005). The MFG secretion process is distinct from the classical secretory pathway used for LD secretion by hepatocytes and enterocytes (Hussain, 2014). One of the cardinal differences between MFG and other secreted lipid-protein assemblies is the former's size range. In principle, the size range of various lipid-protein assemblies, such as lipoproteins in the plasma, is narrow, and any deviation from the normal phenotype is associated with cellular dysfunction (Reddy and Rao, 2006; den Hartigh et al., 2010; Liang and Nishino, 2010; Cohen et al., 2011). The mammary gland is the exception, in that healthy MEC synthesize and secrete MFG in wide range of sizes spanning over 3 orders of magnitude (Mulder and Walstra, 1974).

In milk, the general assumption is that MFG size is positively correlated with total fat content (Spitsberg, 2005; Michalski, 2007; Argov et al., 2008). However, this association does not always hold true (King, 1957; Walstra, 1969; Logan et al., 2014): other factors, such as surface area proteins and the ratio between fat and protein in milk, may play a role in determining MFG size (Couvreur and Hurtaud, 2017). Therefore, MFG size regulation involves various points of regulation at the molecular, genetic, and metabolic levels.

The study of MFG size regulation is complicated by the various factors that affect this unique feature of milk fat. In addition, the study of MFG size in vitro using MEC primary culture or cell lines is limited because these models are inconsistent with respect to metabolic regulation and their secretory capacity for fats and proteins (reviewed by Cohen et al., 2018). Nevertheless, a deep mechanistic understanding of the mechanisms controlling the morphometric features of the MFG can be achieved by studying its precursor, the intracellular LD. In fact, MFG size is determined before and during its secretion from the MEC by the size of the intracellular LD. Hence, the regulation of LD size in MEC can be studied as a proxy for MFG size regulation. Moreover, the initial steps of LD synthesis are common to many cell types, including mammary gland, adipose, muscle, and liver. Thus, advances achieved in understanding the size regulation of $\mathrm{LD}$ in other tissues can provide understanding of the mechanisms underlying intracel- lular LD size regulation and, consequently, the size of the secreted MFG in the mammary gland.

\section{REGULATION OF INTRACELLULAR LD SIZE}

Three main mechanisms are involved in the regulation of intracellular LD size: (1) co-regulation with intracellular Tg levels, (2) membrane material availability, and (3) fusion. These mechanisms are thoroughly reviewed below, although it should be noted that most of the available data on fusion regulation were obtained from synthetic lipid systems (i.e., liposomes) or from recombinant organisms, genetically engineered to induce LD fusion or completely block this phenomenon. Almost none of the mechanistic studies were performed in wild-type cells or organisms and almost none involved mammalian tissues. It follows that studies on LD-fusion mechanisms in the mammary gland model are extremely scarce.

\section{Co-Regulation with Intracellular Tg Levels}

A higher $\mathrm{Tg}$ concentration in the cell is likely to be expressed as a larger LD, as has been demonstrated in larval fat bodies of Drosophila (Krahmer et al., 2011). The $\mathrm{Tg}$ level is determined by the balance between its synthesis and hydrolysis. Synthesis of $\mathrm{Tg}$ occurs in several steps, executed by the activity of glycerol3-phosphate O-acyltransferase (GPAT), 1-acylglycerol3 -phosphate O-acyltransferase, phosphatidic acid phosphatase, and acyl-CoA:diacylglycerol O-acyltransferase (DGAT). Each of these enzymes has multiple isoenzymes that catalyze a specific step in the Tg-synthesis pathway (Yen et al., 2008). At least 1 isoenzyme of each step co-localizes with cytoplasmic LD and contributes to their enlargement by local synthesis of $\mathrm{Tg}$ (Wilfling et al., 2013). Accordingly, overexpression of the Tg-synthesis gene GPAT induced the formation of supersized LD in yeast, preadipocyte cell line, and fly salivary glands (Pagac et al., 2016).

Lipid droplets can also grow in size through the incorporation of $\mathrm{Tg}$ from the endoplasmic reticulum (Gross et al., 2011). In addition, mitochondria are usually found near LD. This proximity is suggested to result in the direct supply of energy and NADPH for the Tg-synthesis enzymes (Walther and Farese, 2009). The physical proximity between the LD and mitochondria, as well as their biochemical link, can provide a biochemical basis for the increased MFG size observed in association with negative energy balance (Argov-Argaman et al., 2014). In addition, MEC treated with free oleic acid had higher numbers of mitochondria, higher expression of the mitochondrial activity marker NADH 
dehydrogenase (ubiquinone) $1 \alpha$ subcomplex, assembly factor 3 (NDUFAF3), and increased LD size compared with MEC treated with free palmitic acid (Cohen et al., 2015); the latter showed a much smaller response in terms of LD number and size distribution compared with the control. These results are in accordance with those from human hepatocyte and monocyte cell lines, as well as a Drosophila cell line (Fujimoto et al., 2006; Guo et al., 2008; McDonough et al., 2009; den Hartigh et al., 2010).

The extent of $\mathrm{Tg}$ hydrolysis also regulates LD size. The hydrolysis occurs via neutral lipolysis in the cytoplasm and acid lipolysis in the lysosome; these processes are catalyzed by different lipase proteins (Zechner et al., 2017). Increasing cyclic AMP levels in differentiated adipocytes in the model cell line 3T3-L1 induced neutral lipolysis and reduced LD size (Paar et al., 2012). Neutral lipolysis is executed by the LD-binding protein CGI-58, which activates adipose triglyceride lipase (ATGL; Paar et al., 2012), whereas $\mathrm{G}_{0} / \mathrm{G}_{1}$ switch protein and perilipin 5 inhibit this lipase (Yang et al., 2010; Wang et al., 2011). Accordingly, mice that were deficient in adipophilin, a member of the perilipin family of LD-binding proteins, failed to produce large LD in their mammary glands; this was correlated with ATGL localization to the LD surface (Russell et al., 2011), suggesting that adipophilin regulates ATGL-dependent lipolysis and can therefore contribute to the regulation of LD size in MEC.

\section{Membrane Material Availability}

The major constituent of intracellular LD envelop is $\mathrm{Pl}$. As such, limited bioavailability of $\mathrm{Pl}$ may result in modulation of LD size. The possible involvement of $\mathrm{Pl}$-synthesis capacity in LD size has been demonstrated in several model organisms. For example, genetic interventions that reduced the expression of the phosphatidylcholine (PC) synthesis genes cho2 and opi3 in yeast and CCTA in mouse macrophages resulted in highly enlarged LD (Fei et al., 2011; Krahmer et al., 2011). In addition, decreased PC levels following CCT1 knockdown in Drosophila S2 cells or sams1 knockdown in nematodes induced the formation of large LD (Guo et al., 2008; Krahmer et al., 2011; Walker et al., 2011). Although extensively studied, the ability to project from these studies onto wild-type living organisms is limited due to the fact study models were based on mutant or recombinant organisms. Specifically for milk and MEC, no information is available regarding conditions that limit Pl synthesis and MFG size, although such an association might explain some of the observations linking MFG size and total fat yield (Argov-Argaman et al., 2014). Moreover, knocked-down capacity of PC synthesis may result in altered $\mathrm{Pl}$ composition in the cells, which has implications in terms of membrane stability and, consequently, fusion between cellular organelles, which may induce changes in LD size.

\section{Fusion}

We showed that treating MEC with free oleic acid induced changes in membrane composition concomitant with the biosynthesis of larger LD compared with treatment with palmitic acid (Cohen et al., 2015). Because, in that study, no change was observed in Tg content between treatments, it was suggested that fusion was the predominant pathway responsible for the altered LD size (Figure 2, pathway 5). The finding that the percentage of LD engaged in fusion increased 4 fold with oleic acid versus palmitic acid treatment (Cohen et al., 2017) supported this assumption. In that study, the peroxisome proliferator-activated receptor pathway was suggested as the molecular mechanism underlying these differences in LD size, which will be discussed further on (see the "Regulation of MFG Size in the Metabolic Context" section).

The LD fusion process includes several stages. First, the $2 \mathrm{LD}$ come in close proximity and the aqueous film separating them is depleted. Second, a pore opens in the membranes, directly linking the core of the 2 LD. Finally, complete fusion occurs as the pore expands, forming 1 larger droplet from the 2 original ones (Thiam et al., 2013). Alternatively, pores can exist transiently without inducing droplet fusion. Whether a pore expands and leads to fusion depends on the physical properties of the $\mathrm{Pl}$ constituents of the LD Pl monolayer. For example, phosphatidylethanolamine (PE) is a negatively curved, cone-like Pl with a small head group that contributes to membrane instability and thus induces LD fusion. The PE has been shown to promote fusion of liposomes with enveloped viruses (White et al., 1982; Alford et al., 1994) and reticulocyte endocytic vesicles (Vidal and Hoekstra, 1995), as well as ER-derived transition vesicles with the Golgi apparatus (Moreau et al., 1992). In contrast, $\mathrm{PC}$ is a cylindrical-like $\mathrm{Pl}$ that stabilizes the membrane and therefore inhibits fusion (Thiam et al., 2013). In liposomes and synthetic systems, the PCto-PE mass ratio has been shown to affect membrane stability and fusion. Furthermore, a study that examined calcium-induced fusion of liposomes composed of different ratios of $\mathrm{PC}$ and phosphatidylserine (PS) found that inclusion of $25 \%$ PC drastically hindered fusion compared with pure PS vesicles. Inclusion of $50 \%$ PC completely inhibited fusion, although the vesicles formed large aggregates (Düzgüneş et al., 1981). Another study examined polyethylene glycol-mediated fusion of liposomes composed of different ratios of PC 
to $\mathrm{PE}$ and showed that fusogenicity increases with decreasing PC-to-PE ratio (Haque et al., 2001). Although membrane instability facilitates fusion, a high level of instability also induces membrane rupture, manifested by content leakage. The optimal balance between fusion and rupture was found at a PC-to-PE molar ratio of 35:30 (Haque et al., 2001).

In the cellular context, it should be emphasized that the mitochondria play a central role in modulating the Pl composition of cellular membranes (Figure 2, pathway 4). Specifically, PS to PE conversion takes place in the mitochondria via phosphatidylserine decarboxylase (PSD; Pereira et al., 2012), and therefore can contribute to regulation of LD stability. The notion that mitochondria contribute to the regulation of LD size via modulation of LD stability has yet to be confirmed, especially in mammals and the mammary gland. More specifically, studies linking metabolic signals and energy metabolism of mammary cells to $\mathrm{Pl}$ composition and membrane stability would shed light on the underlying mechanisms inducing changes in MFG size under various metabolic and energy balance conditions. Moreover, the responses of these pathways to various biotic stressors, through mitochondrial activation or inhibition, might improve our understanding of how MFG size is determined in vivo.

\section{Importance of Membrane Composition in Fusion Regulation}

As mentioned, treating MEC with free oleic acid induced changes in cellular membrane composition concomitant with increased LD size as compared with MEC treated with palmitic acid (Cohen et al., 2015). As no change in $\mathrm{Tg}$ content was observed between treatments, we suggested that changes in membrane composition were enough to alter LD size. Typically, oleic acid increases PE content in MEC, reduces membrane stability, and increases fusion rates between LD (Cohen et al., 2017). To assess the direct connection between membrane stability and fusion, the synthesis and degradation pathways of $\mathrm{PE}$ and $\mathrm{PC}$ were knocked down (Cohen et al., 2017). Synthesis of PC by sequential methylation of phosphatidic acid via the phosphatidylethanolamine $N$-methyltransferase pathway was inhibited by 3-deazaadenosine (Schanche et al., 1982). This treatment was carried out in choline-deficient medium to reduce de novo synthesis of PC (Zhu et al., 2003). Inhibition of the PC synthesis pathway resulted in an increase in PE levels, which increased LD size (Cohen et al., 2017), in agreement with previous studies in Drosophila S2 cells, Caenorhabditis elegans, and mouse liver (Guo et al., 2008; Krahmer et al., 2011; Walker et al., 2011). The increase in LD size in this case might have resulted from an instable $\mathrm{Pl}$ monolayer surrounding the LD, higher fusion rates, or as compensation of the cell for the loss of membrane-synthesis capacity, resulting in reduced LD surface area-to-volume ratio and enlarged LD. These findings are in agreement with bovine mammary gland explants that were treated with methionine, a methyl donor for PC synthesis (Cohen et al., 2017).

Treating MEC with deazaadenosine also increased cellular Tg levels, which in and of itself can increase the intracellular LD diameter. Therefore, the alternative pathway of PE synthesis - the mitochondrial PDS enzyme that converts PS to PE and is exclusively responsible for PE synthesis in culture (Leonardi et al., 2009) — was knocked down (Cohen et al., 2017). This was achieved by either $\mathrm{NaN}_{3}$ and $\mathrm{NaF}$ treatment, which inhibits the transfer of the PSD substrate PS to the mitochondria (Voelker, 1985), or by gene knockdown by short interfering RNA. Both treatments reduced LD size independent of cellular Tg level (Cohen et al., 2017). Taken together, these chemical and genetic approaches suggest that fusion, modulated by cellular membrane composition, has a central role in the regulation of LD size that is independent of cellular $\mathrm{Tg}$ content.

\section{The Role of Mitochondria in Regulating Membrane Composition and Fusion}

The activity of PSD can be modulated by mitochondrial activity or amount. One of the main cellular modulators of mitochondrial biogenesis are the peroxisome proliferator-activated receptor gamma coactivator (PGC)-1 $\beta$ and PGC- $1 \alpha$, which have emerged as master regulators of mitochondrial biogenesis and function (Fernandez-Marcos and Auwerx, 2011). Both PGC-1 $\beta$ and PGC- $1 \alpha$ strongly activate mitochondrial biogenesis and cellular respiration (Lin et al., 2003; StPierre et al., 2003), and the differences between these co-activators in terms of expression and role in the mammary gland are still unclear (Harvatine and Bauman, 2006; Rodriguez-Cruz et al., 2006). Interestingly, $P P A R G C 1 A$ and PPARGC1B expression is regulated by FFA, and induction is dependent on the specificity of the FFA (Lin et al., 2005; Collins et al., 2006). Accordingly, upon priming MEC with free palmitic or oleic acid, mitochondrial quantity increases, with a more pronounced effect for oleic acid compared with palmitic acid (Cohen et al., 2015). Similar patterns between treatments were found in the expression level of NDUFAF3, which is often used as a marker for mitochondrial activity (Hadsell et al., 2011).

These findings shed light on the perplexing phenomenon of secretion of large MFG during early lactation stages (Martini et al., 2009), concomitant with 
negative energy balance and increased plasma NEFA concentrations (Fenwick et al., 2008); a higher NEFA concentration can increase mitochondrial activity and PE content, which destabilizes the cell membranes, including the LD Pl monolayer, and induces LD fusion before their secretion as MFG. It should be stressed that other mechanisms controlling LD size exist, such as regulation by PAT family of lipid droplet proteins (PAT), cell death-inducing DFF45-like effector (CIDE) A (Gao et al., 2017), and SNAP receptor (SNARE) proteins (Boström et al., 2007; Hong and Lev, 2014), as well as fission, which has been demonstrated in 3T3-L1 adipocytes (Marcinkiewicz et al., 2006). Nevertheless, their activity and regulation cannot explain the increased MFG size under negative energy balance during early lactation. Alternatively, increased mitochondrial number and activity during early lactation (Hadsell et al., 2011) are suggested to affect membrane composition and, hence, stability, thereby affecting LD fusion and ultimately the size of the secreted MFG. The data presented herein suggest that the mitochondria are involved in several steps of LD formation and remodeling of its $\mathrm{Pl}$ monolayer, and therefore can play a central role in modulating LD size.

\section{REGULATION OF MFG SIZE IN THE METABOLIC CONTEXT}

One of the possible links between metabolic signals and MFG size is the composition and concentration of FFA available to mammary cells (pathway 2, Figure 2 ). These can affect the incorporation of FA into $\mathrm{Tg}$ or $\mathrm{Pl}$, as these lipid entities differ in FA composition, (Bitman and Wood, 1990; Mesilati-Stahy et al., 2012). Moreover, the availability of long-chain FA to enzymes that convert a mutual substrate to either $\mathrm{Tg}$ or $\mathrm{Pl}$ (Argov-Argaman et al., 2013) can affect Pl synthesis capacity and, therefore, the size of intracellular LD as well as of secreted MFG.

Many of the studies reporting altered MFG size also reported a change in NEFA concentration. Nevertheless, the associations between NEFA level and MFG diameter were inconsistent; for example, drenching lactating cows with propylene glycol resulted in a negative association between NEFA level and MFG size (Mesilati-Stahy et al., 2015), whereas feeding lactating cows with a low-concentrate, high-forage diet simultaneously increased NEFA concentration and MFG size (Argov-Argaman et al., 2014). Looking at the entire data set in these studies reveals inconsistencies in the 2 nutritional approaches (i.e., propylene glycol and different concentrate-to-forage ratios) with respect to their effects on production traits that may, independently, change MFG size. For example, fat concentration in milk was not affected by propylene glycol administration, whereas cows fed the low-concentrate, high-forage diet produced milk with higher fat content compared with their counterparts fed a high-concentrate, lowforage diet. In addition, drenching with propylene glycol did not change insulin levels, whereas changing the concentrate-to-forage ratio did. Differences in plasma insulin concentration have been associated with differences in milk fat content (Mackle et al., 1999; Karcagi et al., 2010) and MFG size in goats (Argov-Argaman et al., 2012). Therefore, some of the physiological parameters that differed between these in vivo models may themselves have affected MFG size, thereby confounding the effect of NEFA on MFG size.

To isolate this latter effect, we used an in vitro model of MEC primary culture. The main limitation was that the focus had to be shifted from MFG to intracellular LD. To assess the direct effect of NEFA on MFG size, primary cultures of bovine MEC were exposed to similar concentrations and compositions of FA in the form of either Tg, part of VLDL, or FFA.

Exposing MEC to FFA resulted in 2 distinct processes, each of which can independently increase LD size: elevated $\mathrm{Tg}$ production and membrane destabilization (Mesilati-Stahy and Argov-Argaman, 2018). The MEC exposed to FFA had a lower PC-to-PE ratio, suggesting a less stable membrane (Thiam et al., 2013) and higher rates of LD fusion (Cohen et al., 2017). The membrane remodeling was accompanied by higher numbers of mitochondria in the FFA treatment, possibly through the peroxisome proliferator-activated receptor- $\gamma$ coactivator pathway, which is activated by FFA (Lin et al., 2005; Collins et al., 2006). As noted, the mitochondria play a central role in membrane $\mathrm{Pl}$ remodeling, especially through the PSD-facilitated PS to PE conversion (Vance, 2015). Therefore, affecting mitochondrial number or activity can change the composition and physiochemical properties of cellular membranes and the LD Pl monolayer. Taken together, it seems that membrane composition is key to the bioproduction of specific MFG sizes, with NEFA playing a significant role in the ratio between $\mathrm{Tg}$ and $\mathrm{Pl}$ and in $\mathrm{LD}$ fusion, thereby modulating MFG diameter.

\section{CONCLUSIONS}

The MFGM has been established as a strong bioactive component of milk, with beneficial effects for infant health and development. The content of MFGM in milk can be controlled by the size of the secreted MFG, a process that is subject to metabolic regulation of fat synthesis, $\mathrm{Tg}$ hydrolysis, and cellular membrane composition, which determines the fusion of LD before their secretion as MFG. The sum of these processes 
can explain the alterations in MFG-size phenotype under various metabolic conditions. Ultimately, an understanding of the mechanisms controlling the size of intracellular LD and secreted MFG can be used to guide milk composition toward being more beneficial for growth, development, and health using in vivo, preharvest practices. To achieve this, studies on the metabolic signals regulating mitochondrial numbers and activity, intracellular LD assembly and size, and the kinetics of LD secretion will enable a better understanding of MFG size regulation. Concomitantly, studies on the implication of size and the association between size and composition on MFG in digestion, absorption, and postprandial metabolism are warranted.

\section{REFERENCES}

Adewuyi, A. A., E. Gruys, and F. J. Van Eerdenburg. 2005. Non esterified fatty acids (NEFA) in dairy cattle. A review. Vet. Q. 27:117-126. https://doi.org/10.1080/01652176.2005.9695192.

Admyre, C., S. M. Johansson, K. Rahman, Q. Jan-Jonas, F. Riitta, M. Norman, P. A. Etienne, S. Scheynius, and S. Gabrielsson. 2007. Exosomes with immune modulatory features. J. Immunol. 179:1969-1978.

Alford, D., H. Ellens, and J. Bentz. 1994. Fusion of influenza virus with sialic acid-bearing target membranes. Biochemistry 33:19771987. https://doi.org/10.1021/bi00174a002.

Almazov, V. A., I. S. Freǐdlin, and E. I. Krasil'nikova. 1986. Use of lipostabil to correct lipid metabolism disorders in patients with ischemic heart disease. Kardiologiia 26:39-42.

Argov, N., D. G. Lemay, and J. B. German. 2008. Milk fat globule structure and function: nanoscience comes to milk production. Trends Food Sci. Technol. 19:617-623. https://doi.org/10.1016/j .tifs.2008.07.006.

Argov-Argaman, N., O. Hadaya, T. Glasser, H. Muklada, L. Dvash, R. Mesilati-Stahy, and S. Y. Landau. 2016. Milk fat globule size, phospholipid contents and composition of milk from purebred and Alpine-crossbred Mid-Eastern goats under confinement or grazing condition. Int. Dairy J. 58:2-8. https://doi.org/10.1016/j.idairyj .2015 .12 .003

Argov-Argaman, N., T. Mbogori, C. Sabastian, A. Shamay, and S. J. Mabjeesh. 2012. Hyperinsulinemic clamp modulates milk fat globule lipid composition in goats. J. Dairy Sci. 95:5776-5787. https:/ /doi.org/10.3168/jds.2012-5569.

Argov-Argaman, N., R. Mesilati-Stahy, Y. Magen, and U. Moallem. 2014. Elevated concentrate-to-forage ratio in dairy cow rations is associated with a shift in the diameter of milk fat globules and remodeling of their membranes. J. Dairy Sci. 97:6286-6295. https: //doi.org/10.3168/jds.2014-8174

Argov-Argaman, N., K. Mida, B. C. Cohen, M. Visker, and K. Hettinga. 2013. Milk fat content and DGAT1 genotype determine lipid composition of the milk fat globule membrane. PLoS One 8:e68707. https://doi.org/10.1371/journal.pone.0068707.

Armand, M., B. Pasquier, M. André, P. Borel, M. Senft, J. Peyrot, J. Salducci, H. Portugal, V. Jaussan, and D. Lairon. 1999. Digestion and absorption of 2 fat emulsions with different droplet sizes in the human digestive tract. Am. J. Clin. Nutr. 70:1096-1106. https:// doi.org/10.1093/ajen/70.6.1096

Avramis, C. A., H. Wang, B. W. McBride, T. C. Wright, and A. R. Hill. 2003. Physical and processing properties of milk, butter, and Cheddar cheese from cows fed supplemental fish meal. J. Dairy Sci. 86:2568-2576. https://doi.org/10.3168/jds.S0022 -0302(03)73851-X.

Baars, A., A. Oosting, E. Engels, D. Kegler, A. Kodde, L. Schipper, H. J. Verkade, and E. M. van der Beek. 2016. Milk fat globule membrane coating of large lipid droplets in the diet of young mice prevents body fat accumulation in adulthood. Br. J. Nutr. 115:1930-1937. https://doi.org/10.1017/S0007114516001082.

Bengtsson, G., and T. Olivecrona. 1980. Lipoprotein lipase. Eur. J. Biochem. 106:557-562.

Berra, B., I. Colombo, E. Sottocornola, and A. Giacosa. 2002. Dietary sphingolipids in colorectal cancer prevention. Eur. J. Cancer Prev. 11:193-197.

Bhinder, G., J. M. Allaire, C. Garcia, J. T. Lau, J. M. Chan, N. R. Ryz, E. S. Bosman, F. A. Graef, S. M. Crowley, L. S. Celiberto, and J. C. Berkmann. 2017. Milk fat globule membrane supplementation in formula modulates the neonatal gut microbiome and normalizes intestinal development. Sci. Rep. 7:45274. https://doi .org/10.1038/srep45274.

Billeaud, C., G. Puccio, E. Saliba, B. Guillois, C. Vaysse, S. Pecquet, and P. Steenhout. 2014. Safety and tolerance evaluation of milk fat globule membrane-enriched infant formulas: a randomized controlled multicenter non-inferiority trial in healthy term infants. Clin. Med. Insights. Pediatr. 8:51-60.

Bitman, J., and D. L. Wood. 1990. Changes in milk fat phospholipids during lactation. J. Dairy Sci. 73:1208-1216. https://doi.org/10 .3168/jds.S0022-0302(90)78784-X.

Bobkova, V. I., L. I. Lokshina, V. N. Korsunskiı̌, and G. V. Tananova 1989. Metabolic effect of lipostabil-forte. Kardiologiia 29:57-60.

Boström, P., L. Andersson, M. Rutberg, J. Perman, U. Lidberg, B R. Johansson, J. Fernandez-Rodriguez, J. Ericson, T. Nilsson, J. Borén, and S. O. Olofsson. 2007. SNARE proteins mediate fusion between cytosolic lipid droplets and are implicated in insulin sensitivity. Nat. Cell Biol. 9:1286. https://doi.org/10.1038/ncb1648.

Cohen, B. C., C. Raz, A. Shamay, and N. Argov-Argaman. 2017. Lipid droplet fusion in mammary epithelial cells is regulated by phosphatidylethanolamine metabolism. J. Mammary Gland Biol Neoplasia 22:235-249. https://doi.org/10.1007/s10911-017-9386-7.

Cohen, B. C., A. Shamay, and N. Argov-Argaman. 2015. Regulation of lipid droplet size in mammary epithelial cells by remodeling of membrane lipid composition-A potential mechanism. PLoS One 10:e0121645. https://doi.org/10.1371/journal.pone.0121645.

Cohen, B. C., A. Shamay, and N. Argov-Argaman. 2018. Lipid metabolism in mammary epithelial cells-A comparison of common in vitro models. J. Adv. Dairy Res. https://doi.org/10.4172/2329 -888 X.1000202.

Cohen, J. C., J. D. Horton, and H. H. Hobbs. 2011. Human fatty liver disease: Old questions and new insights. Science 332:1519-1523. https://doi.org/10.1126/science.1204265.

Cohn, J. S., E. Wat, A. Kamili, and S. Tandy. 2008. Dietary phospholipids, hepatic lipid metabolism and cardiovascular disease. Curr. Opin. Lipidol. 19:257-262. https://doi.org/10.1097/MOL .0b013e3282ffaf96.

Collins, Q. F., Y. Xiong, E. G. Lupo, H. Y. Liu, and W. Cao. 2006. p38 Mitogen-activated protein kinase mediates free fatty acid-induced gluconeogenesis in hepatocytes. J. Biol. Chem. 281:24336-24344. https://doi.org/10.1074/jbc.M602177200.

Corl, B. A., S. T. Butler, W. R. Butler, and D. E. Bauman. 2006 Regulation of milk fat yield and fatty acid composition by insulin. J. Dairy Sci. 89:4172-4175. https://doi.org/10.3168/jds.S0022 $-0302(06) 72462-6$.

Couvreur, S., and C. Hurtaud. 2017. Relationships between milks differentiated on native milk fat globule characteristics and fat, protein and calcium compositions. Animal 11:507-518.

Couvreur, S., C. Hurtaud, P. G. Marnet, P. Faverdin, and J. L. Peyraud. 2007. Composition of milk fat from cows selected for milk fat globule size and offered either fresh pasture or a corn silage-based diet. J. Dairy Sci. 90:392-403. https://doi.org/10.3168/jds.S0022 -0302(07)72640-1.

den Hartigh, L. J., J. E. Connolly-Rohrbach, S. Fore, T. R. Huser, and J. C. Rutledge. 2010. Fatty acids from very low-density lipoprotein lipolysis products induce lipid droplet accumulation in human monocytes. J. Immunol. 184:3927-3936. https://doi.org/10.4049/ jimmunol.0903475.

Dougherty, R. M., C. Galli, A. Ferro-Luzzi, and J. M. Iacono. 1987. Lipid and phospholipid fatty acid composition of plasma, red blood cells, and platelets and how they are affected by dietary lipids: a 
study of normal subjects from Italy, Finland, and the USA. Am. J. Clin. Nutr. 45:443-455. https://doi.org/10.1093/ajcn/45.2.443.

Düzgüneş, N., J. Wilschut, R. Fraley, and D. Papahadjopoulos. 1981. Studies on the mechanism of membrane fusion. Role of head-group composition in calcium-and magnesium-induced fusion of mixed phospholipid vesicles. Biochim. Biophys. Acta 642:182-195. https: //doi.org/10.1016/0005-2736(81)90148-6.

Fauquant, C., V. Briard, N. Leconte, and M. C. Michalski. 2005. Differently sized native milk fat globules separated by microfiltration: Fatty acid composition of the milk fat globule membrane and triglyceride core. Eur. J. Lipid Sci. Technol. 107:80-86. https://doi .org/10.1002/ejlt.200401063.

Fei, W., G. Shui, Y. Zhang, N. Krahmer, C. Ferguson, T. S. Kapterian, R. C. Lin, I. W. Dawes, A. J. Brown, P. Li, and X. Huang. 2011. A role for phosphatidic acid in the formation of "supersized" lipid droplets. PLoS Genet. 7:e1002201. https://doi.org/10.1371/ journal.pgen.1002201.

Fenwick, M. A., R. Fitzpatrick, D. A. Kenny, M. G. Diskin, J. Patton, J. J. Murphy, and D. C. Wathes. 2008. Interrelationships between negative energy balance (NEB) and IGF regulation in liver of lactating dairy cows. Domest. Anim. Endocrinol. 34:31-44. https:// doi.org/10.1016/j.domaniend.2006.10.002.

Fernandez-Marcos, P. J., and J. Auwerx. 2011. Regulation of PGC-1 $\alpha$, a nodal regulator of mitochondrial biogenesis. Am. J. Clin. Nutr. 93:884S-90. https://doi.org/10.3945/ajcn.110.001917.

Fujimoto, Y., J. Onoduka, K. J. Homma, S. Yamaguchi, M. Mori, Y. Higashi, M. Makita, T. Kinoshita, J. I. Noda, H. Itabe, and T. Takanoa. 2006. Long-chain fatty acids induce lipid droplet formation in a cultured human hepatocyte in a manner dependent of Acyl-CoA synthetase. Biol. Pharm. Bull. 29:2174-2180.

Fukunaga, K., Z. Hossain, and K. Takahashi. 2008. Marine phosphatidylcholine suppresses 1, 2-dimethylhydrazine-induced colon carcinogenesis in rats by inducing apoptosis. Nutr. Res. 28:635-640 https://doi.org/10.1016/j.nutres.2008.05.005.

Gao, G., F. J. Chen, L. Zhou, L. Su, D. Xu, L. Xu, and P. Li. 2017. Control of lipid droplet fusion and growth by CIDE family proteins. Biochim. Biophys. Acta Mol. Cell. Biol. Lipids 1862:11971204.

Gross, D. A., C. Zhan, and D. L. Silver. 2011. Direct binding of triglyceride to fat storage-inducing transmembrane proteins 1 and 2 is important for lipid droplet formation. Proc. Natl. Acad. Sci. USA 108:19581-19586.

Guo, Y., T. C. Walther, M. Rao, N. Stuurman, G. Goshima, K. Terayama, J. S. Wong, R. D. Vale, P. Walter, and R. V. Farese. 2008. Functional genomic screen reveals genes involved in lipid-droplet formation and utilization. Nature 453:657-661. https://doi.org/10 .1038 /nature06928.

Hadsell, D. L., W. Olea, J. Wei, M. L. Fiorotto, R. K. Matsunami, D. A. Engler, and R. J. Collier. 2011. Developmental regulation of mitochondrial biogenesis and function in the mouse mammary gland during a prolonged lactation cycle. Physiol. Genomics 43:271-285. https://doi.org/10.1152/physiolgenomics.00133.2010.

Hammond, L. E., P. A. Gallagher, S. Wang, S. Hiller, K. D. Kluckman, E. L. Posey-Marcos, N. Maeda, and R. A. Coleman. 2002 Mitochondrial glycerol-3-phosphate acyltransferase-deficient mice have reduced weight and liver triacylglycerol content and altered glycerolipid fatty acid composition. Mol. Cell. Biol. 22:8204-8214.

Haque, M. E., T. J. McIntosh, and B. R. Lentz. 2001. Influence of lipid composition on physical properties and peg-mediated fusion of curved and uncurved model membrane vesicles: "Nature's own" fusogenic lipid bilayer. Biochemistry 40:4340-4348.

Harvatine, K. J., and D. E. Bauman. 2006. SREBP1 and thyroid hormone responsive spot 14 (S14) are involved in the regulation of bovine mammary lipid synthesis during diet-induced milk fat depression and treatment with CLA. J. Nutr. 136:2468-2474. https: //doi.org/10.1093/jn/136.10.2468.

Heid, H. W., and T. W. Keenan. 2005. Intracellular origin and secretion of milk fat globules. Eur. J. Cell Biol. 84:245-258. https://doi .org/10.1016/j.ejcb.2004.12.002.

Hernell, O., N. Timby, M. Domellöf, and B. Lönnerdal. 2016. Clinical benefits of milk fat globule membranes for infants and children.
J. Pediatr. 173:S60-S65. https://doi.org/10.1016/j.jpeds.2016.02 .077 .

Hong, W., and S. Lev. 2014. Tethering the assembly of SNARE complexes. Trends Cell Biol. 24:35-43.

Hussain, M. M. 2014. Intestinal lipid absorption and lipoprotein formation. Curr. Opin. Lipidol. 25:200-206. https://doi.org/10.1097/ MOL.0000000000000084

Jiang, Y., S. K. Noh, and S. I. Koo. 2001. Egg phosphatidylcholine decreases the lymphatic absorption of cholesterol in rats. J. Nutr. 131:2358-2363. https://doi.org/10.1093/jn/131.9.2358.

Karcagi, R. G., T. Gaál, P. Ribiczey, G. Huszenicza, and F. Husvéth. 2010. Milk production, peripartal liver triglyceride concentration and plasma metabolites of dairy cows fed diets supplemented with calcium soaps or hydrogenated triglycerides of palm oil. J. Dairy Res. 77:151-158. https://doi.org/10.1017/S0022029909990604.

King, J. O. L. 1957. The association between the fat percentage of cows' milk and the size and number of the fat globules. J. Dairy Res. 24:198-200. https://doi.org/10.1016/j.tifs.2008.07.006.

Kinsella, J. E. 1974. Biosynthesis of fatty acids in rat mammary cells. Int. J. Biochem. 5:417-421.

Klimov, A. N., V. O. Konstantinov, B. M. Lipovetsky, A. S. Kuznetsov, V. T. Lozovsky, V. F. Trufanov, S. L. Plavinsky, K. J. Gundermann, and R. Schumacher. 1995. "Essential" phospholipids versus nicotinic acid in the treatment of patients with type IIb hyperlipoproteinemia and ischemic heart disease. Cardiovasc. Drugs Ther. 9:779-784.

Knowles, S. O., N. D. Grace, T. W. Knight, W. C. McNabb, and J. Lee. 2004. Adding nutritional value to meat and milk from pasture-fed livestock. N. Z. Vet. J. 52:342-351. https://doi.org/10 $.1080 / 00480169.2004 .36450$.

Knowles, S. O., N. D. Grace, T. W. Knight, W. C. McNabb, and J. Lee. 2006. Reasons and means for manipulating the micronutrient composition of milk from grazing dairy cattle. Anim. Feed Sci Technol. 131:154-167. https://doi.org/10.1016/j.anifeedsci.2006 .04 .015 .

Krahmer, N., Y. Guo, F. Wilfling, M. Hilger, S. Lingrell, K. Heger, H. W. Newman, M. Schmidt-Supprian, D. E. Vance, M. Mann, and R. V. Farese. 2011. Phosphatidylcholine synthesis for lipid droplet expansion is mediated by localized activation of CTP: phosphocholine cytidylyltransferase. Cell Metab. 14:504-515. https://doi .org/10.1016/j.cmet.2011.07.013.

Küllenberg, D., L. A. Taylor, M. Schneider, and U. Massing. 2012. Health effects of dietary phospholipids. Lipids Health Dis. 11:3. https://doi.org/10.1186/1476-511X-11-3.

Leece, J. G. 1973. Effect of dietary regimen on cessation of uptake of macromolecules by piglet intestinal epithelium (closure) and transport to the blood. J. Nutr. 103:751-756. https://doi.org/10 $.1093 / \mathrm{jn} / 103.5 .751$

Leonardi, R., M. W. Frank, P. D. Jackson, C. O. Rock, and S. Jackowski. 2009. Elimination of the CDP-ethanolamine pathway disrupts hepatic lipid homeostasis. J. Biol. Chem. 284:27077-27089. https://doi.org/10.1074/jbc.M109.031336.

Li, T., J. Gao, M. Du, J. Song, and X. Mao. 2018. Milk fat globule membrane attenuates high-fat diet-induced obesity by inhibiting adipogenesis and increasing uncoupling protein 1 expression in white adipose tissue of mice. Nutrients 10:331. https://doi.org/10 $.3390 /$ nu10030331.

Liang, W. C., and I. Nishino. 2010. State of the art in muscle lipid diseases. Acta Myol. 29:351-356.

Lin, J., P. T. Tarr, R. Yang, J. Rhee, P. Puigserver, C. B. Newgard, and B. M. Spiegelman. 2003. PGC-1 $\beta$ in the regulation of hepatic glucose and energy metabolism. J. Biol. Chem. 278:30843-30848. https://doi.org/10.1074/jbc.M303643200.

Lin, J., R. Yang, P. T. Tarr, P. H. Wu, C. Handschin, S. Li, W. Yang, L. Pei, M. Uldry, P. Tontonoz, and C. B. Newgard. 2005. Hyperlipidemic effects of dietary saturated fats mediated through PGC$1 \beta$ coactivation of SREBP. Cell 120:261-273. https://doi.org/10 .1016/j.cell.2004.11.043.

Logan, A., M. Auldist, J. Greenwood, and L. Day. 2014. Natural variation of bovine milk fat globule size within a herd. J. Dairy Sci. 97:4072-4082. https://doi.org/10.3168/jds.2014-8010. 
Lopez, C., V. Briard-Bion, O. Menard, F. Rousseau, P. Pradel, and J. M. Besle. 2008. Phospholipid, sphingolipid, and fatty acid compositions of the milk fat globule membrane are modified by diet. J. Agric. Food Chem. 56:5226-5236. https://doi.org/10.1021/ jf7036104.

Lopez, C., and O. Ménard. 2011. Human milk fat globules: Polar lipid composition and in situ structural investigations revealing the heterogeneous distribution of proteins and the lateral segregation of sphingomyelin in the biological membrane. Colloids Surf. B Biointerfaces 83:29-41. https://doi.org/10.1016/j.colsurfb.2010.10.039.

Lu, J., N. Argov-Argaman, J. Anggrek, S. Boeren, T. van Hooijdonk, J. Vervoort, and K. A. Hettinga. 2016. The protein and lipid composition of the membrane of milk fat globules depends on their size. J. Dairy Sci. 99:4726-4738. https://doi.org/10.3168/jds.2015 -10375 .

Mackle, T. R., D. A. Dwyer, K. L. Ingvartsen, P. Y. Chouinard, J. M. Lynch, D. M. Barbano, and D. E. Bauman. 1999. Effects of insulin and amino acids on milk protein concentration and yield from dairy cows. J. Dairy Sci. 82:1512-1524. https://doi.org/10.3168/ jds.S0022-0302(99)75378-6.

Marcinkiewicz, A., D. Gauthier, A. Garcia, and D. L. Brasaemle. 2006. The phosphorylation of serine 492 of perilipin a directs lipid droplet fragmentation and dispersion. J. Biol. Chem. 281:11901-11909. https://doi.org/10.1074/jbc.M600171200.

Martini, M., F. Salari, and C. Scolozzi. 2009. Goat milk: Morphometric characteristics of milk fat globules. Sci. Tec. Latt.-Casearia 60:31-35.

Masedunskas, A., Y. Chen, R. Stussman, R. Weigert, and I. H. Mather. 2017. Kinetics of milk lipid droplet transport, growth, and secretion revealed by intravital imaging: Lipid droplet release is intermittently stimulated by oxytocin. Mol. Biol. Cell 28:935-946. https://doi.org/10.1091/mbc.E16-11-0776.

Mather, I. H., and T. W. Keenan. 1998. Origin and secretion of milk lipids. J. Mammary Gland Biol. Neoplasia 3:259-273.

McDonough, P. M., R. M. Agustin, R. S. Ingermanson, P. A. Loy, B. M. Buehrer, J. B. Nicoll, N. L. Prigozhina, I. Mikic, and J. H. Price. 2009. Quantification of lipid droplets and associated proteins in cellular models of obesity via high-content/high-throughput microscopy and automated image analysis. Assay Drug Dev. Technol. 7:440-460. https://doi.org/10.1089/adt.2009.0196.

McManaman, J. L. 2009. Formation of milk lipids: A molecular perspective. Clin. Lipidol. 4:391-401. https://doi.org/10.2217/clp.09 .15 .

McManaman, J. L. 2012. Milk lipid secretion; recent biomolecular aspects. Biomol. Concepts 3:581-591.

Mesilati-Stahy, R., and N. Argov-Argaman. 2018. Changes in lipid droplets morphometric features in mammary epithelial cells upon exposure to non-esterified free fatty acids compared with VLDL. PLoS One. https://doi.org/10.1371/journal.pone.0209565.

Mesilati-Stahy, R., H. Malka, and N. Argov-Argaman. 2012. Association of plasma insulin concentration to fatty acid distribution between milk fat and membrane synthesis. J. Dairy Sci. 95:17671775. https://doi.org/10.3168/jds.2011-4583.

Mesilati-Stahy, R., H. Malka, and N. Argov-Argaman. 2015. Influence of glucogenic dietary supplementation and reproductive state of dairy cows on the composition of lipids in milk. Animal 9:1008 1015. https://doi.org/10.1017/S1751731115000099.

Mesilati-Stahy, R., K. Mida, and N. Argov-Argaman. 2011. Size-dependent lipid content of bovine milk fat globule and membrane phospholipids. J. Agric. Food Chem. 59:7427-7435. https://doi .org/10.1021/jf201373j.

Michalski, M. C. 2007. On the supposed influence of milk homogenization on the risk of CVD, diabetes and allergy. Br. J. Nutr. 97:598. https://doi.org/10.1017/S0007114507657900.

Michalski, M. C., V. Briard, F. Michel, F. Tasson, and P. Poulain. 2005. Size distribution of fat globules in human colostrum, breast milk, and infant formula. J. Dairy Sci. 88:1927-1940. https://doi .org/10.3168/jds.S0022-0302(05)72868-X.

Michalski, M. C., J. Y. Gassi, M. H. Famelart, N. Leconte, B. Camier, F. Michel, and V. Briard. 2003. The size of native milk fat glob- ules affects physico-chemical and sensory properties of Camembert cheese. Lait 83:131-143. https://doi.org/10.1051/lait:2003003.

Monks, J., M. Dzieciatkowska, E. S. Bales, D. J. Orlicky, R. M. Wright, and J. L. McManaman. 2016. Xanthine oxidoreductase mediates membrane docking of milk-fat droplets but is not essential for apocrine lipid secretion. J. Physiol. 594:5899-5921. https://doi.org/10 $.1113 /$ JP272390.

Moreau, P., H. Juguelin, C. Cassagne, and D. J. Morré. 1992. Molecular basis for low temperature compartment formation by transitional endoplasmic reticulum of rat liver. FEBS Lett. 310:223-228. https://doi.org/10.1016/0014-5793(92)81337-L.

Motouri, M., H. Matsuyama, J. I. Yamamura, M. Tanaka, S. Aoe, T. Iwanaga, and H. Kawakami. 2003. Milk sphingomyelin accelerates enzymatic and morphological maturation of the intestine in artificially reared rats. J. Pediatr. Gastroenterol. Nutr. 36:241-247.

Mulder, H., and P. Walstra. 1974. The fat dispersion. Pages 54-66 in The Milk Fat Globule. Emulsion Science as Applied to Milk Products and Comparable Foods. H. Mulder, P. Walstra, ed. Center for Agricultural Publishing and Documentation, Wageningen, the Netherlands.

Noh, S. K., and S. I. Koo. 2003. Egg sphingomyelin lowers the lymphatic absorption of cholesterol and $\alpha$-tocopherol in rats. J. Nutr. 133:3571-3576. https://doi.org/10.1093/jn/133.11.3571.

O'Mahony, J. A., M. A. Auty, and P. L. McSweeney. 2005. The manufacture of miniature Cheddar-type cheeses from milks with different fat globule size distributions. J. Dairy Res. 72:338-348. https: //doi.org/10.1017/S0022029905001044.

Olofsson, S. O., and J. Borén. 2012. Apolipoprotein B secretory regulation by degradation. Arterioscler. Thromb. Vasc. Biol. 32:13341338. https://doi.org/10.1161/ATVBAHA.112.251116.

Paar, M., C. Jüngst, N. A. Steiner, C. Magnes, F. Sinner, D. Kolb, A. Lass, R. Zimmermann, A. Zumbusch, S. D. Kohlwein, and H. Wolinski. 2012. Remodeling of lipid droplets during lipolysis and growth in adipocytes. J. Biol. Chem. 287:11164-11173. https://doi .org/10.1074/jbc.M111.316794.

Pagac, M., D. E. Cooper, Y. Qi, I. E. Lukmantara, H. Y. Mak, Z. Wu, Y. Tian, Z. Liu, M. Lei, X. Du, and C. Ferguson. 2016. SEIPIN regulates lipid droplet expansion and adipocyte development by modulating the activity of glycerol-3-phosphate acyltransferase. Cell Reports 17:1546-1559.

Patton, S., and R. G. Jensen. 1975. Lipid metabolism and membrane functions of the mammary gland. Prog. Chem. Fats Other Lipids $14: 163-277$

Penick, S. B., and L. E. Hinkle Jr.. 1963. The effect of glucagon, phenmetrazine and epinephrine on hunger, food intake and plasma non-esterified fatty acids. Am. J. Clin. Nutr. 13:110-114. https:// doi.org/10.1093/ajen/13.2.110.

Pereira, L., J. P. Girardi, and M. Bakovic. 2012. Forms, crosstalks, and the role of phospholipid biosynthesis in autophagy. Int. J. Cell Biol. 2012. https://doi.org/10.1155/2012/931956.

Peterson, J., B. E. Bihain, G. Bengtsson-Olivecrona, R. J. Deckelbaum, Y. A. Carpentier, and T. Olivecrona. 1990. Fatty acid control of lipoprotein lipase: a link between energy metabolism and lipid transport. Proc. Natl. Acad. Sci. USA 87:909-913.

Reddy, J. K., and M. S. Rao. 2006. Lipid metabolism and liver inflammation. II. Fatty liver disease and fatty acid oxidation. Am. J. Physiol. Gastrointest. Liver Physiol. 290:G852-G858. https://doi .org/10.1152/ajpgi.00521.2005.

Reinhardt, T. A., and J. D. Lippolis. 2008. Developmental changes in the milk fat globule membrane proteome during the transition from colostrum to milk. J. Dairy Sci. 91:2307-2318. https://doi .org/10.3168/jds.2007-0952.

Rodriguez-Cruz, M., A. R. Tovar, B. Palacios-González, M. del Prado, and N. Torres. 2006. Synthesis of long-chain polyunsaturated fatty acids in lactating mammary gland: Role of $\Delta 5$ and $\Delta 6$ desaturases, SREBP-1, PPAR $\alpha$, and PGC-1. J. Lipid Res. 47:553-560. https:/ /doi.org/10.1194/jlr.M500407-JLR200.

Ruby, M. A., B. Goldenson, G. Orasanu, T. P. Johnston, J. Plutzky, and R. M. Krauss. 2010. VLDL hydrolysis by LPL activates PPAR- $\alpha$ through generation of unbound fatty acids. J. Lipid Res. 51:2275-2281. https://doi.org/10.1194/jlr.M005561. 
Ruiz-Sala, P., M. T. Hierro, I. Martinez-Castro, and G. Santa-Maria. 1996. Triglyceride composition of ewe, cow, and goat milk fat. J. Am. Oil Chem. Soc. 73:283-293. https://doi.org/10.1007/ BF02523421.

Russell, T. D., J. Schaack, D. J. Orlicky, C. Palmer, B. H. J. Chang, L. Chan, and J. L. McManaman. 2011. Adipophilin regulates maturation of cytoplasmic lipid droplets and alveolae in differentiating mammary glands. J. Cell Sci. 124:3247-3253. https://doi.org/10 $1242 /$ jcs.082974.

Sakakima, Y., A. Hayakawa, T. Nagasaka, and A. Nakao. 2007. Prevention of hepatocarcinogenesis with phosphatidylcholine and menaquinone-4: In vitro and in vivo experiments. J. Hepatol. 47:83-92. https://doi.org/10.1016/j.jhep.2007.01.030.

Sakakima, Y., A. Hayakawa, and A. Nakao. 2009. Phosphatidylcholine induces growth inhibition of hepatic cancer by apoptosis via death ligands. Hepatogastroenterology 56:481-484.

Salvia-Trujillo, L., C. Qian, O. Martín-Belloso, and D. J. McClements. 2013. Influence of particle size on lipid digestion and $\beta$-carotene bioaccessibility in emulsions and nanoemulsions. Food Chem. 141:1472-1480. https://doi.org/10.1016/j.foodchem.2013.03.050.

Salvia-Trujillo, L., S. H. Verkempinck, L. Sun, A. M. Van Loey, T. Grauwet, and M. E. Hendrickx. 2017. Lipid digestion, micelle formation and carotenoid bioaccessibility kinetics: Influence of emulsion droplet size. Food Chem. 229:653-662. https://doi.org/10 .1016/j.foodchem.2017.02.146.

Schanche, J. S., T. Schanche, and P. M. Ueland. 1982. Inhibition of phospholipid methylation in isolated rat hepatocytes by analogues of adenosine and S-adenosylhomocysteine. Biochim. Biophys. Acta 721:399-407.

Smoczyński, M. 2017. Role of phospholipid flux during milk secretion in the mammary gland. J. Mammary Gland Biol. Neoplasia 22:117-129. https://doi.org/10.1007/s10911-017-9376-9.

Spitsberg, V. L. 2005. Invited review: Bovine milk fat globule membrane as a potential nutraceutical. J. Dairy Sci. 88:2289-2294. https://doi.org/10.3168/jds.S0022-0302(05)72906-4.

St-Pierre, J., J. Lin, S. Krauss, P. T. Tarr, R. Yang, C. B. Newgard, and B. M. Spiegelman. 2003. Bioenergetic analysis of peroxisome proliferator-activated receptor $\gamma$ coactivators $1 \alpha$ and $1 \beta$ (PGC- $1 \alpha$ and PGC-1 $\beta$ ) in muscle cells. J. Biol. Chem. 278:26597-26603. https://doi.org/10.1074/jbc.M301850200.

Takeuchi, K., and K. Reue. 2009. Biochemistry, physiology, and genetics of GPAT, AGPAT, and lipin enzymes in triglyceride synthesis. Am. J. Physiol. Endocrinol. Metab. 296:E1195-E1209. https://doi .org/10.1152/ajpendo.90958.2008.

Tanaka, K., M. Hosozawa, N. Kudo, N. Yoshikawa, K. Hisata, H. Shoji, K. Shinohara, and T. Shimizu. 2013. The pilot study: Sphingomyelin-fortified milk has a positive association with the neurobehavioural development of very low birth weight infants during infancy, randomized control trial. Brain Dev. 35:45-52. https://doi .org/10.1016/j.braindev.2012.03.004.

Teusink, B., P. J. Voshol, V. E. Dahlmans, P. C. Rensen, H. Pijl, J. A. Romijn, and L. M. Havekes. 2003. Contribution of fatty acids released from lipolysis of plasma triglycerides to total plasma fatty acid flux and tissue-specific fatty acid uptake. Diabetes 52:614620

Thiam, A. R., R. V. Farese Jr., and T. C. Walther. 2013. The biophysics and cell biology of lipid droplets. Nat. Rev. Mol. Cell Biol. 14:775-786.

Timby, N. 2016. New Infant Formula with MFGM Improves Protection Against Infections. New Results from the Tummy Study. Hero, Institute for Infant Nutrition, Alcantarilla, Spain.

Timby, N., E. Domellöf, O. Hernell, B. Lönnerdal, and M. Domellöf. 2014. Neurodevelopment, nutrition, and growth until 12 mo of age in infants fed a low-energy, low-protein formula supplemented with bovine milk fat globule membranes: a randomized controlled trial. Am. J. Clin. Nutr. 99:860-868.

Vance, J. E. 2015. Phospholipid synthesis and transport in mammalian cells. Traffic 16:1-18.

Vidal, M., and D. Hoekstra. 1995. In vitro fusion of reticulocyte endocytic vesicles with liposomes. J. Biol. Chem. 270:17823-17829.

Voelker, D. R. 1985. Disruption of phosphatidylserine translocation to the mitochondria in baby hamster kidney cells. J. Biol. Chem. 260:14671-14676.

Walker, A. K., R. L. Jacobs, J. L. Watts, V. Rottiers, K. Jiang, D. M. Finnegan, T. Shioda, M. Hansen, F. Yang, L. J. Niebergall, and D. E. Vance. 2011. A conserved SREBP-1/phosphatidylcholine feedback circuit regulates lipogenesis in metazoans. Cell 147:840-852. https://doi.org/10.1016/j.cell.2011.09.045.

Walstra, P. 1969. Studies on milk fat dispersion. ii. Globule-size distribution of cow's milk. Netherlands Milk Dairy J. 23:99-110.

Walther, T. C., and R. V. Farese. 2009. The life of lipid droplets. Biochim. Biophys. Acta 1791:459-466.

Wang, H., M. Bell, U. Sreenevasan, H. Hu, J. Liu, K. Dalen, C. Londos, T. Yamaguchi, M. A. Rizzo, R. Coleman, and D. Gong. 2011. Unique regulation of adipose triglyceride lipase (ATGL) by perilipin 5, a lipid droplet-associated protein. J. Biol. Chem. 286:1570715715. https://doi.org/10.1074/jbc.M110.207779.

Ward, C. 2015. Lipolysis and lipogenesis. Diapedia https://doi.org/10 $.14496 /$ dia.51040851148.17.

White, J., J. Kartenbeck, and A. Helenius. 1982. Membrane fusion activity of influenza virus. EMBO J. 1:217-222.

Wiking, L., J. Stagsted, L. Björck, and J. H. Nielsen. 2004. Milk fat globule size is affected by fat production in dairy cows. Int. Dairy J. 14:909-913. https://doi.org/10.1016/j.idairyj.2004.03.005.

Wilfling, F., H. Wang, J. T. Haas, N. Krahmer, T. J. Gould, A. Uchida, J. X. Cheng, M. Graham, R. Christiano, F. Fröhlich, and X. Liu. 2013. Triacylglycerol synthesis enzymes mediate lipid droplet growth by relocalizing from the ER to lipid droplets. Dev. Cell 24:384-399. https://doi.org/10.1016/j.devcel.2013.01.013.

Wu, C. C., K. E. Howell, M. C. Neville, J. R. Yates III, and J. L. McManaman. 2000. Proteomics reveal a link between the endoplasmic reticulum and lipid secretory mechanisms in mammary epithelial cells. Electrophoresis 21:3470-3482. https://doi.org/10.1002/1522 -2683(20001001)21:16<3470::AID-ELPS3470>3.0.CO;2-G.

Yang, X., X. Lu, M. Lombès, G. B. Rha, Y. I. Chi, T. M. Guerin, E. J. Smart, and J. Liu. 2010. The G0/G1 switch gene 2 regulates adipose lipolysis through association with adipose triglyceride lipase. Cell Metab. 11:194-205. https://doi.org/10.1016/j.cmet.2010.02 .003 .

Yen, C. L. E., S. J. Stone, S. Koliwad, C. Harris, and R. V. Farese. 2008. Thematic review series: Glycerolipids. DGAT enzymes and triacylglycerol biosynthesis. J. Lipid Res. 49:2283-2301. https:// doi.org/10.1194/jlr.R800018-JLR200.

Zechner, R., F. Madeo, and D. Kratky. 2017. Cytosolic lipolysis and lipophagy: Two sides of the same coin. Nat. Rev. Mol. Cell Biol. 18:671. https://doi.org/10.1038/nrm.2017.76.

Zhang, P., B. Li, S. Gao, and R. D. Duan. 2008. Dietary sphingomyelin inhibits colonic tumorigenesis with an up-regulation of alkaline sphingomyelinase expression in ICR mice. Anticancer Res. 28:3631-3635

Zhu, X., J. Song, M. H. Mar, L. J. Edwards, and S. H. Zeisel. 2003. Phosphatidylethanolamine N-methyltransferase (PEMT) knockout mice have hepatic steatosis and abnormal hepatic choline metabolite concentrations despite ingesting a recommended dietary intake of choline. Biochem. J. 370:987-993. https://doi.org/10 .1042/BJ20021523. 